\title{
GEODIVERSIDADE NA PRAIA DE MARACAÍPE: UM ESTUDO DE CASO NO LITORAL SUL DE PERNAMBUCO
}

\author{
Carlos de Oliveira Bispo ${ }^{(a)}$, Ítalo Rodrigo Paulino de Arruda ${ }^{(b)}$, Gerlando Rodrigues de Lima ${ }^{(b)}$ Thaís de \\ Oliveira Guimarães ${ }^{(\mathrm{c})}$
}

(a) Mestrando em Geografia, Departamento de Ciências Geográficas, Universidade Federal de Pernambuco, Email: bispocarlos93@gmail.com

(b) Estudante de Geografia, Departamento de Ciências Geográficas, Universidade Federal de Pernambuco, Email: italotavares0811@gmail.com; rodriguesgerlando@gmail.com

(c) Doutora em Geociências, Programa de Geociências, Universidade Federal de Pernambuco, Email: thaisguimaraes.geo@gmail.com

Eixo: GEODIVERSIDADE, GEOARQUEOLOGIA E PATRIMÔNIO NATURAL

\begin{abstract}
Resumo
A Praia de Maracaípe apresenta uma grande diversidade de elementos da Geodiversidade, além de uma relevante biodiversidade local, dependente basicamente do ecossistema manguezal. Geologicamente a praia está inserida na Bacia Sedimentar de Pernambuco. É um ambiente bastante dinâmico que sofre erosão, sedimentação e equilíbrio. A Zona Costeira é um espaço de grande valor ambiental, além de exercer um importante papel socioeconômico na forma de enorme fonte de recursos para moradores da região. A Praia de Maracaípe é conhecida por suas áreas de manguezal, berçário natural de várias espécies, além da praia e da prática do Surf que atraí diversos turistas para a região. Tratando-se de uma praia com grande diversidade de ecossistemas naturais, emerge a necessidade estratégias de geoconservação e incetivo a prática do geoturismo visando à garantia dos elementos da biodiversidade e geodiversidade, bem como o incentivo às práticas do desenvolvimento sustentável.
\end{abstract}

Palavras Chaves: Biodiversidade, Geodiversidade, Maracaípe, Pernambuco.

\section{Introdução}

A zona costeira corresponde a transição entre a faixa do domínio continental e marinho. É uma área complexa, bastante dinâmica do ponto de vista geomorfológico e variável em relação aos processos geológicos. Configura-se como um espaço fonte de recursos para moradores e um ambiente extremamente sensível e instável pelo seu caráter de interface terra-mar (MANSO, et al., 2010).

O meio natural compreende de uma maneira geral todos os elementos bióticos (com vida) e abióticos (sem vida) do Planeta, bem como os processos a ele relacionados. Assim, os elementos vivos presentes na Terra constituem a Biodiversidade, enquanto os elementos abióticos representam a Geodiversidade 
(GUIMARÃES, 2016). É essencial considerarmos a importância da relação entre a Biodiversidade e a Geodiversidade de um ambiente, pois ambas exercem um papel fundamental para a dinâmica de um geoambiente.

Segundo Guimarães (2016), o progresso da valorização e crescimento das discussões a cerca da geodiversidade, de seus valores e direta influência na Biodiversidade ainda precisam atingir maiores níveis, tanto no meio acadêmico quanto na sociedade. Por outro lado, mesmo que a Biodiversidade ainda tenha uma maior influência e atenção às medidas conservacionistas, a Geodiversidade já tem começado a conquistar seu lugar sendo destaque em projetos e programas importantes mundialmente, como por exemplo, o Programa Mundial de Geoparques UNESCO, que tem o patrimônio geológico como um de seus principais pilares estruturante.

A Zona Costeira como espaço de interação antrópica, exerce um importante papel socioeconômico na forma de enorme fonte de recursos para a comunidade local. Quando se trata de diversidade biológica engloba-se a flora, fauna e/ou qualquer organismo vivo. A vegetação da Praia de Maracaípe é composta por vegetação nativa de Mata Atlântica e formações litorâneas (extensos manguezais). A Praia de Maracaípe é muito conhecida por suas áreas de mangue, berçário natural de várias espécies, resultando assim, zonas com constantes atividades biológicas.

Seguindo a linha de pensamento de Guimarães (2016), toda a variedade abiótica e natural da terra, seja ela geológica, geomorfológica, pedológica, águas superficiais, bem como outros sistemas, resultantes dos processos naturais endogénos e exogénos é compreendido como Geodiversidade. No que afirma Gray (2005), a Geodiversidade permite incluir a diversidade natural na conservação, no planejamento e educação através de diferentes formas, por exemplo: geossítios, patrimônio geológico, geoparques e áreas protegidas.

Para que estas unidades aqui apresentadas sejam asseguradas às futuras gerações, se faz necessário políticas públicas e privadas para a geoconservação, através, por exemplo, do geoturismo. A atividade geoturística configura-se como uma importante ferramenta de geoconservação, difusão do conhecimento e desenvolvimento territorial sustentável, tendo como objetivos divulgar, valorizar e conservar os elementos naturais do meio abiótico. Os principais atrativos da atividade são as feições geológicas, formas geomorfológicas, fósseis e icnofósseis, mas ao contrário do que o prefixo "geo" a princípio infere, vão muito mais além (PIEKARZ; LICCARDO, 2007; RUCHKYS, 2007; DECLARAÇÃO DE AROUCA, 2011). 
Com base na temática da Geodiversidade, foi realizado um estudo com objetivo de ressaltar a relevância da "Praia de Maracaípe" devido a sua grande Biodiversidade dependente do ecossistema mangue, sua geomorfologia costeira e propor a geoconservação de seus elementos da Geodiversidade e o geoturismo como atividade de desenvolvimento sustentável.

\section{2. Área de Estudo}

A área de estudo está inserida na Bacia Sedimentar de Pernambuco em sua porção centro-sul. A Praia de Maracaípe está localizada no Litoral Sul de Pernambuco, no munícipio de Ipojuca, há aproximadamente $70 \mathrm{~km}$ do Recife, capital do Estado (Figura 1).

\section{LITORAL SUL DE PERNAMBUCO}

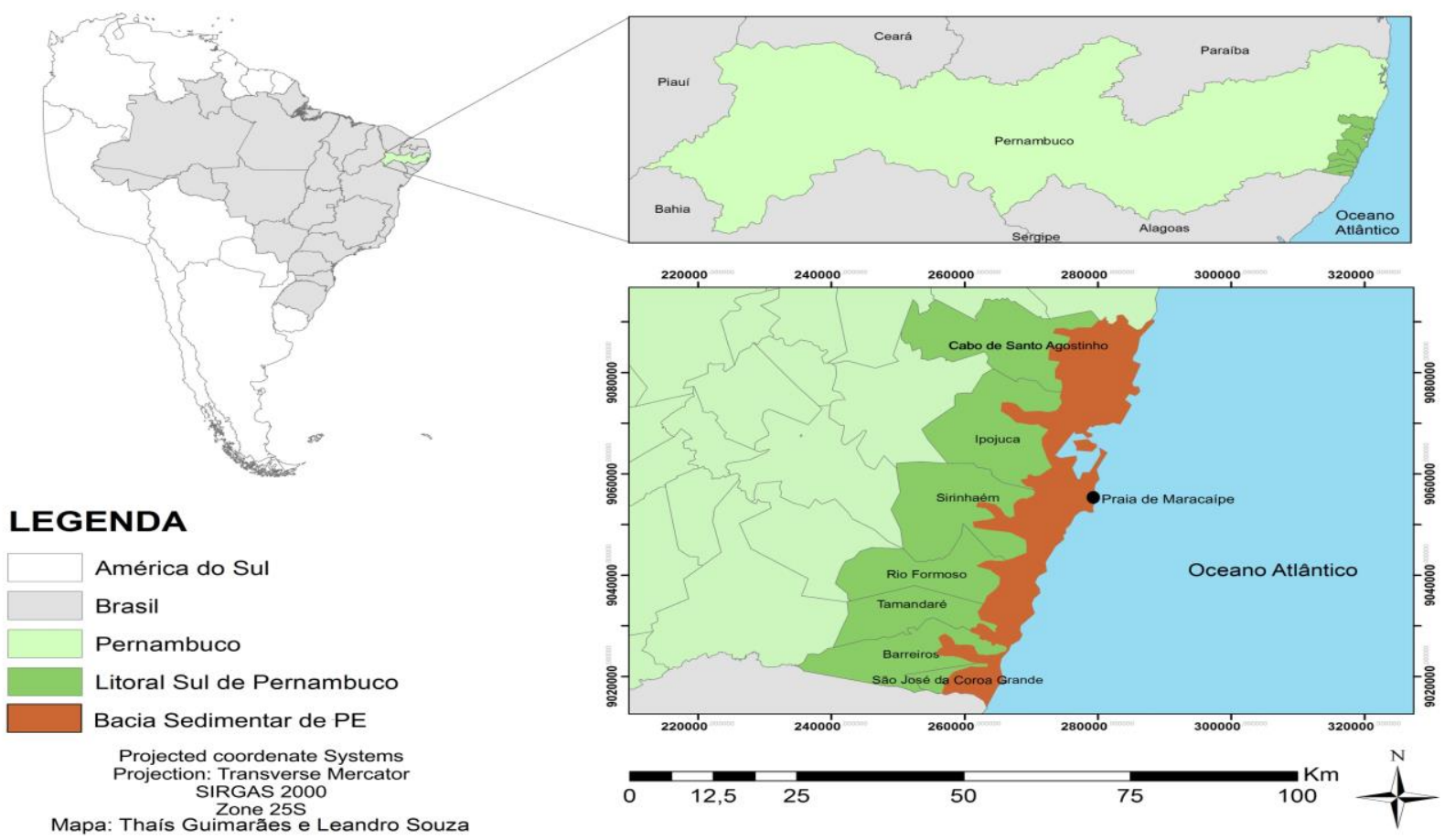

Figura 1. Localização dos municípios do Litoral Sul de Pernambuco e área aproximada da Bacia Sedimentar de Pernambuco no setor centro-sul - detalhe para localização da praia de Maracaípe (Adaptado: Guimarães, 2016).

Em forma de enseada, com aproximadamente $4 \mathrm{~km}$ de extensão, Maracaípe está situada sobre a planície costeira que se formou durante o período Quaternário (Figura 2). Transgressões e regressões marinhas retrabalharam o Grupo Barreiras durante este período, Bittencourt et al. (1983) e Dominguez et al. (1990), formando os terraços marinhos arenosos, sendo o produto da última Transgressão os cordões holocênicos, quando o nível do mar atingiu $5 \mathrm{~m}$ acima do nível atual a aproximadamente 5.000 anos A.P. 
A principal via de acesso ao litoral sul é a BR-101 e em seguida a rodovia estadual PE-60 que começa próximo ao centro do Cabo de Santo Agostinho ou a via transoceânica PE-009, sob administração da concessionária Rota do Atlântico. Outra forma de chegar às praias é pela via litorânea, saindo do Recife pelas praias de Piedade e Candeias em direção Sul até a Ponte do Paiva, que dá acesso ao Litoral Sul

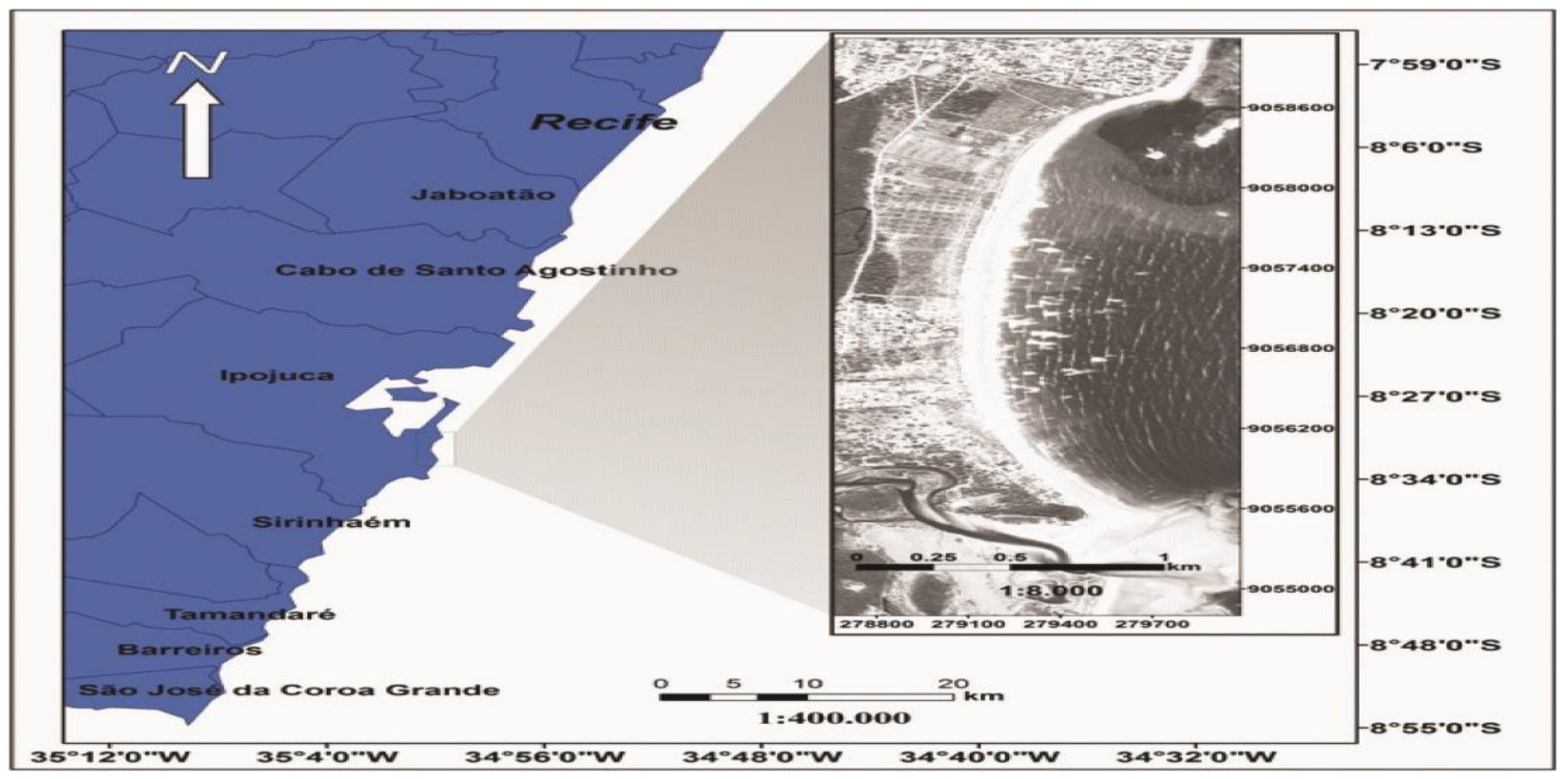

através da Reserva do Paiva, já no município do Cabo de Santo Agostinho.

Figura 2. Localização da Praia de Maracaípe no município de Ipojuca-Pernambuco (Fonte: Adaptado de Macêdo 2011).

\section{Material e Métodos}

Esta pesquisa foi realizada através de uma detalhada investigação bibliográfica, por meio de documentos e artigos referentes à área, pesquisas em campo e registros fotográficos, com o objetivo de descrever e comparar os comportamentos e diferenças que a Praia de Maracaípe tem apresentado no seu ecossistema no decorrer dos anos, tanto na realidade presente, como do passado.

Realizou-se uma exploração de aproximadamente 1000 metros da área com intuito de observar e reconhecer a zona de praia. A atividade foi desenvolvida entre os dias 05 a 08 de novembro de 2016 (Figura 3). Foram selecionados três pontos, e realizadas análises a respeito de diversas caraterísticas fundamentais para a dinâmica praial. Observou-se as dinâmicas do espaço geomorfológico costeiro no local, envolvendo aspectos naturais, biológicos e antrópicos (Quadro 1). Na compreensão dos sedimentos 


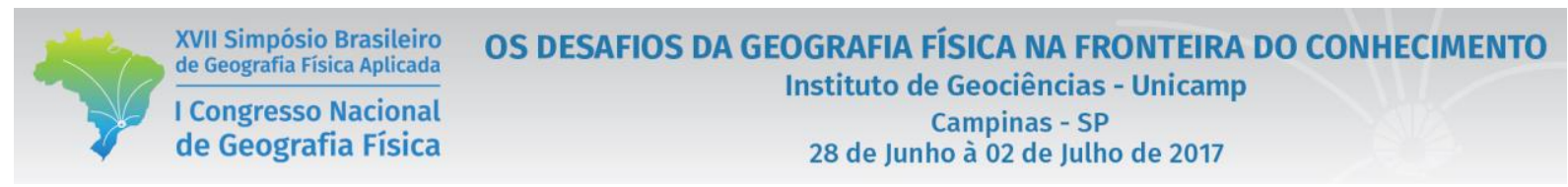

praiais, procurou-se utilizar trabalhos recentes com intuito de compreender as análises sedimentológicas que descrevem as diversas unidades deposicionais existentes nessa faixa litorânea.

Para caracterizar a granulometria dos depósitos praiais utilizou-se dados de Macêdo (2011), que realizou coletas com cerca de $300 \mathrm{~g}$ de sedimentos ao longo das seguintes morfologias da faixa de praia: pós-praia, estirâncio superior, médio e inferior; totalizando quatro amostras por perfil. As coletas foram realizadas durante o verão (período seco), na tentativa de identificar variações significativas nos processos de sedimentação. As amostras foram colocadas pra secagem ao ar livre por, no mínimo, $48 \mathrm{~h}$ a fim de retirar toda a umidade para evitar alteração no peso real. Em seguida, subamostras de $100 \mathrm{~g}$ foram quarteadas e lavadas para dissolução dos sais e peneiramento úmido dos sedimentos finos (silte e argila) com peneiras no intervalo de 3 a $4 \varphi$ e, para os grosseiros (cascalho), -1 a $0 \varphi$. As subamostras foram guardadas em estufas a temperatura de $60^{\circ}$ para secagem por $48 \mathrm{~h}$. Retirada toda a umidade, fez-se o peneiramento seco

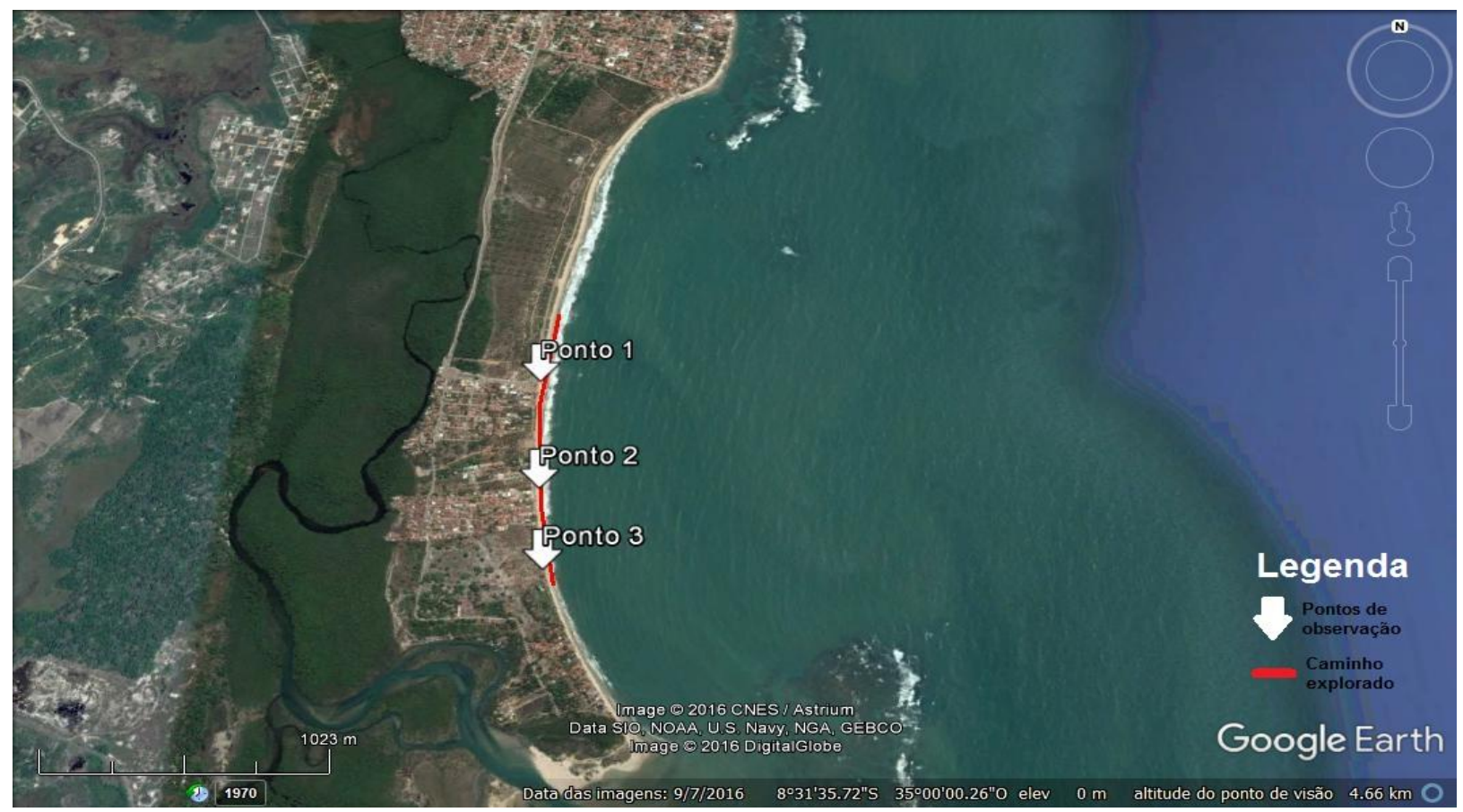

com peneiras nos intervalos inteiros de phi: $-1 \varphi, 0$ a $1 \varphi, 1$ a $2 \varphi, 2$ a $3 \varphi$ e 3 a $4 \varphi$, correspondendo respectivamente à areia muito grossa, areia grossa, areia média, areia fina e areia muito fina. Os dados obtidos do fracionamento das amostras foram inseridos no software SYSGRAN versão 3.0 (CAMARGO, 2006 apud MACÊDO, 2011) para análise estatística de acordo com as equações de (FOLK \& WARD, 1957 apud MACÊDO, 2011).

Figura 3: Áreas selecionadas para observação e análise do espaço. Fonte: Google Earth, 2017.

Quadro 1: Caracterização dos pontos observados na Praia de Maracaípe. 


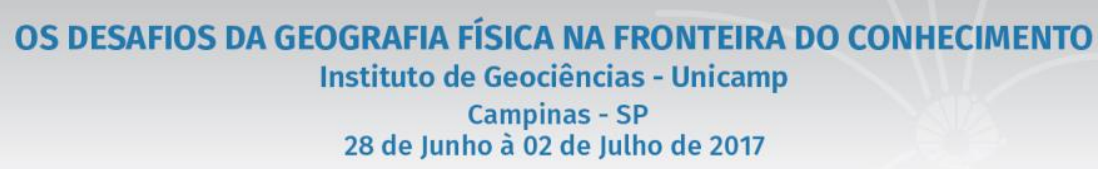

\begin{tabular}{|c|c|c|c|c|}
\hline & $\begin{array}{c}\text { Coordenadas } \\
\text { Geográficas }\end{array}$ & $\begin{array}{c}\text { Estruturas naturais } \\
\text { (Beachrocks) }\end{array}$ & $\begin{array}{c}\text { Aspectos } \\
\text { biológicos }\end{array}$ & $\begin{array}{c}\text { Uso da Orla } \\
\text { (Ação Antrópica) }\end{array}$ \\
\hline PONTO1 & $\begin{array}{c}\text { Lat: } 8^{\circ} 31^{\prime} 31.80^{\prime \prime} \mathrm{S} \\
\text { Long: } 35^{\circ} 026.14^{\prime \prime} \mathrm{O}\end{array}$ & Ausente & Presente & Presente \\
\hline PONTO2 & $\begin{array}{c}\text { Lat: } 8^{\circ} 31^{\prime} 48.23^{\prime \prime} \mathrm{S} \\
\text { Long: } 35^{\circ} 025.28^{\prime \prime} \mathrm{O}\end{array}$ & Presente & Presente & Presente \\
\hline PONTO3 & $\begin{array}{c}\text { Lat: } 8^{\circ} 31^{\prime} 59.95^{\prime \prime} \mathrm{S} \\
\text { Long: } 35^{\circ} 024.13^{\prime \prime} \mathrm{O}\end{array}$ & Presente & Presente & Presente \\
\hline
\end{tabular}

Fonte: Autores (2016).

No que se refere à metodologia, tomou-se por base o trabalho de Macêdo (2010) que classificou os sedimentos desta área de acordo com o tamanho dos grãos através da escala de WENTWORTH (1922), conforme quadro 2 .

Quadro 2: Caracterização dos pontos observados na Praia de Maracaípe

\begin{tabular}{|c|c|c|}
\hline Classificação & Phi (\$) & Milímetros (mm) \\
\hline Areia muito grossa & -1 a 0 & 2 a 1 \\
\hline Areia grossa & O a 1 & 1 a 0,5 \\
\hline Areia média & 1 a 2 & 0,5 a 0,25 \\
\hline Areia fina & 2 a 3 & 0,25 a 0,125 \\
\hline Areia muito fina & 3 a 4 & 0,125 a 0,0625 \\
\hline Silte & 4 a 8 & 0,0625 a 0,0039 \\
\hline Argila & $>8$ & $<0,0039$ \\
\hline
\end{tabular}

Fonte: Adaptado Macêdo (2011)

O enfoque principal foi desenvolver uma maior compreensão sobre a Geodiversidade e a Biodiversidade na Praia de Maracaípe, utilizando bibliografias prévias e umas das principais ferramentas do geógrafo, a observação da dinâmica espacial.

\section{Resultados e Discussão}

A Orla de Maracaípe apresenta uma vasta Biodiversidade e Geodiversidade costeira que está sendo fortemente ameaçada pelos processos de ocupações irregulares, causando o desmatamento da vegetação nativa e intensificação da erosão, além da ausência de uma administração de monitoramento para a geoconservação destes elementos. Por ter um elevado potencial turístico, a Praia de Maracaípe vem se tornando um dos destinos preferidos dos turistas que se aventuram pelo litoral sul de Pernambuco (MÂCEDO, 2010). 


\subsection{Biodiversidade Local}

Os ambientes costeiros são extremamente dinâmicos, neles, os mais variados processos terrestres, oceânicos e atmosféricos convergem simultaneamente, alterando constantemente suas características, Angulo (2004). A Praia de Maracaípe, é composta por floresta subperenifólia e as formações litorâneas (Manso et al., 2010), que são grandes estabilizadores do substrato e o seu sistema de raízes proporciona abrigo para uma grande variedade de fauna muito rica, altamente adaptada às condições do estuário e com espécies de grande valor comercial para a região. Entretanto, é também, uma área de extrema sensibilidade e muito instável pelo seu caráter de interface terra-mar.

\subsubsection{Vegetação}

A Praia de Maracaípe é muito conhecida por suas importantes áreas de manguezal (Figura 4), berçário natural de diversas espécies de animais e vegetais, pois, nesse ambiente, existe uma grande quantidade de microrganismos que decompõe ativamente os restos orgânicos existentes, liberando nutrientes que vão ser aproveitados por inúmeras espécies marinhas, o que torna os manguezais um dos ecossistemas mais produtivos. No ponto de observação 2 e 3 é possível ver as áreas desse bioma que são constantes zonas de atividades biológicas

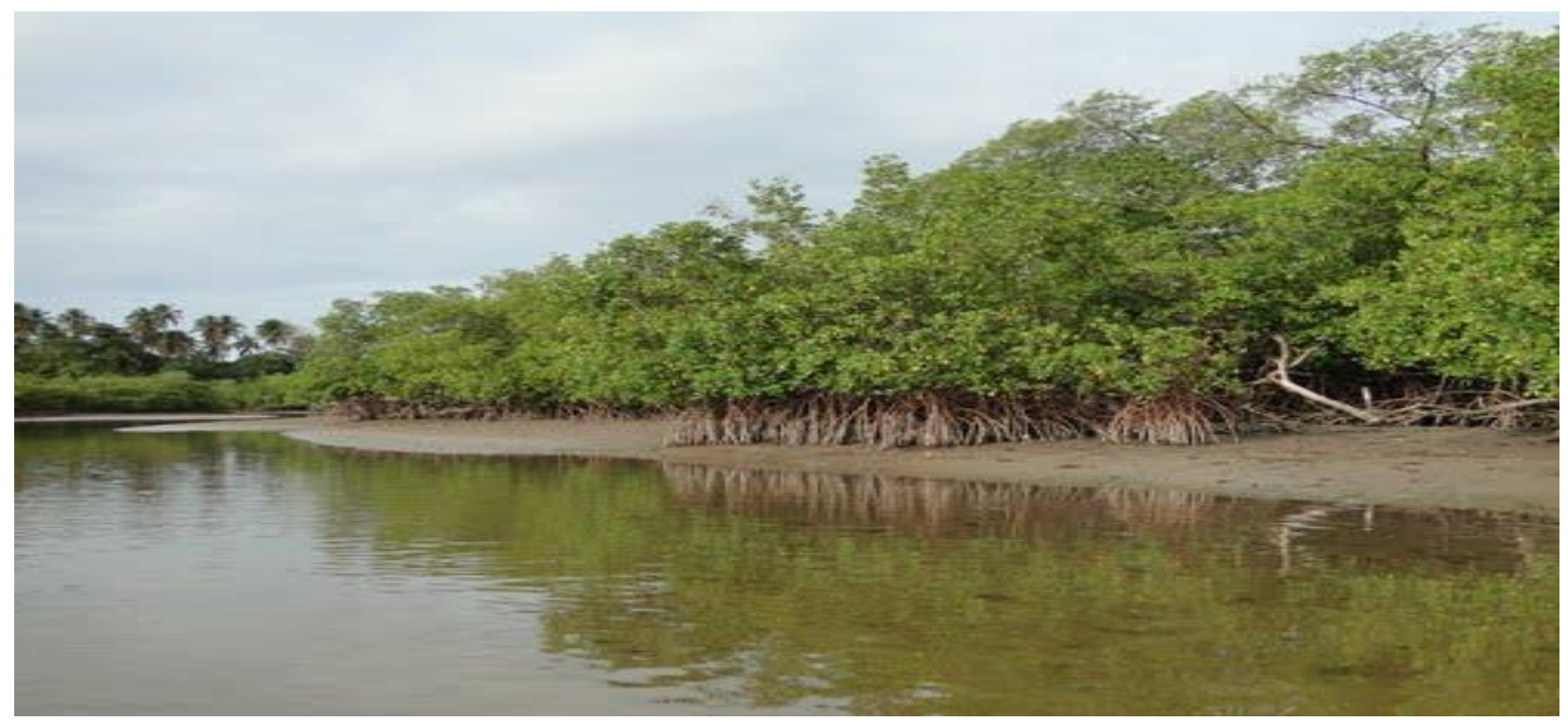

Figura 4: Foto do canal do estuário do rio Maracaípe. Observar as espécies típicas de Manguezal. Fonte: autores, 2017. 
A Praia de Maracaípe apresenta um conjunto de vegetação pouco densa e herbácea (MANSO, 2003). Sua ocorrência tem início geralmente depois das cristas de berma, mais precisamente na pós-praia, e são representados por gramíneas, salsas de praia e capim de areia. O ponto de análise (3) apresenta uma grande extensão das formações litorâneas e da presença de fragmentos da Mata Atlântica. O que torna a região com uma grande variedade de flora totalmente rica. A participação da ação antrópica nessa área ainda é baixa.

\subsection{Geodiversidade Local}

A faixa costeira Sul do Estado de Pernambuco apresenta uma variedade de seus elementos da Geodiversidade, que é formada por uma sequência sedimentar bastante peculiar. Possui forma alongada e paralela à costa. É formada pelos sedimentos holocênicos e por afloramentos, repousando sobre o embasamento que é constituído por rochas do cristalino da Província Borborema, de idade pré-cambriana, e vulcanitos da Formação Ipojuca (MACÊDO, 2010).

\subsubsection{Geologia}

Geologicamente a praia está inserida na Bacia Sedimentar de Pernambuco, localizada entre a Zona de Cisalhamento de Pernambuco ao alto Maragogi, limite com a Bacia de Alagoas (Lima Filho, 1998). É formada por sedimentos holocênicos, as Formações Cabo, Estiva e Algodoais; rochas da Suíte Magmática Ipojuca e afloramentos do Grupo Barreiras, que repousam sobre o embasamento cristalino, constituído por rochas de idade pré-cambriana pertencentes a província da Borborema.

A praia é um ambiente bastante dinâmico que pode sofrer erosão, sedimentação e equilíbrio em curto prazo, através de forças naturais (onda, corrente, maré e vento), e, em longo prazo, em consequência das flutuações do nível relativo do mar (MANSO, et al., 2010). Estes sedimentos encontram-se depositados entre a linha de baixa-mar e os terraços holocênicos, tendo geralmente pequena inclinação no sentido do mar.

Os depósitos atuais formam a estreita faixa da atual zona de praia. Segundo Macêdo (2011), esses depósitos são constituídos por areias quartzosas de granulação fina a média que variam de pobremente selecionadas a moderadamente selecionadas. Um condicionamento importante no processo de erosão costeira é a presença ou não, na plataforma continental interna adjacente, de recifes de arenitos ou algálicos, os quais desenvolvem feições geomorfológicas características, ou seja, tômbolo ou baías, respectivamente. 


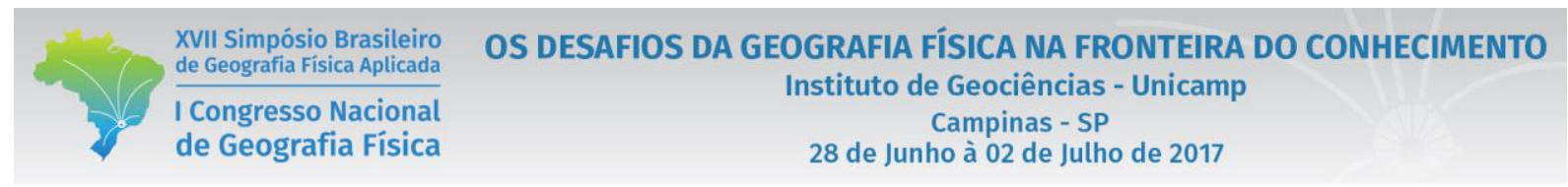

Assim, a área de estudo apresenta a formação dos arenitos de praia (beachrocks) que são rochas sedimentares cimentadas por carbonato de cálcio, que se apresentam de forma alongada e estreita e que se dispõe em linhas paralelas à costa. Os arenitos de praia têm grande importância na compartimentação do litoral, além de serem testemunhas visíveis de um nível relativo do mar mais alto do que o atual durante o Holoceno (Figura 5).

Segundo Guerra et al. (2005), esses aglomerados constituem-se por depósitos de arenitos cimentados por carbonato de cálcio e são indicadores de paleoníveis marinhos, sendo que os mais próximos à costa, são os mais recentes de diagênese fraca, portanto, friáveis.

No ponto de observação (2) já é possível encontrar essa formação de arenitos. Observa-se também que atividade antrópica presente, é mais ativa nos pontos (2) e (3) em comparação ao ponto 1.

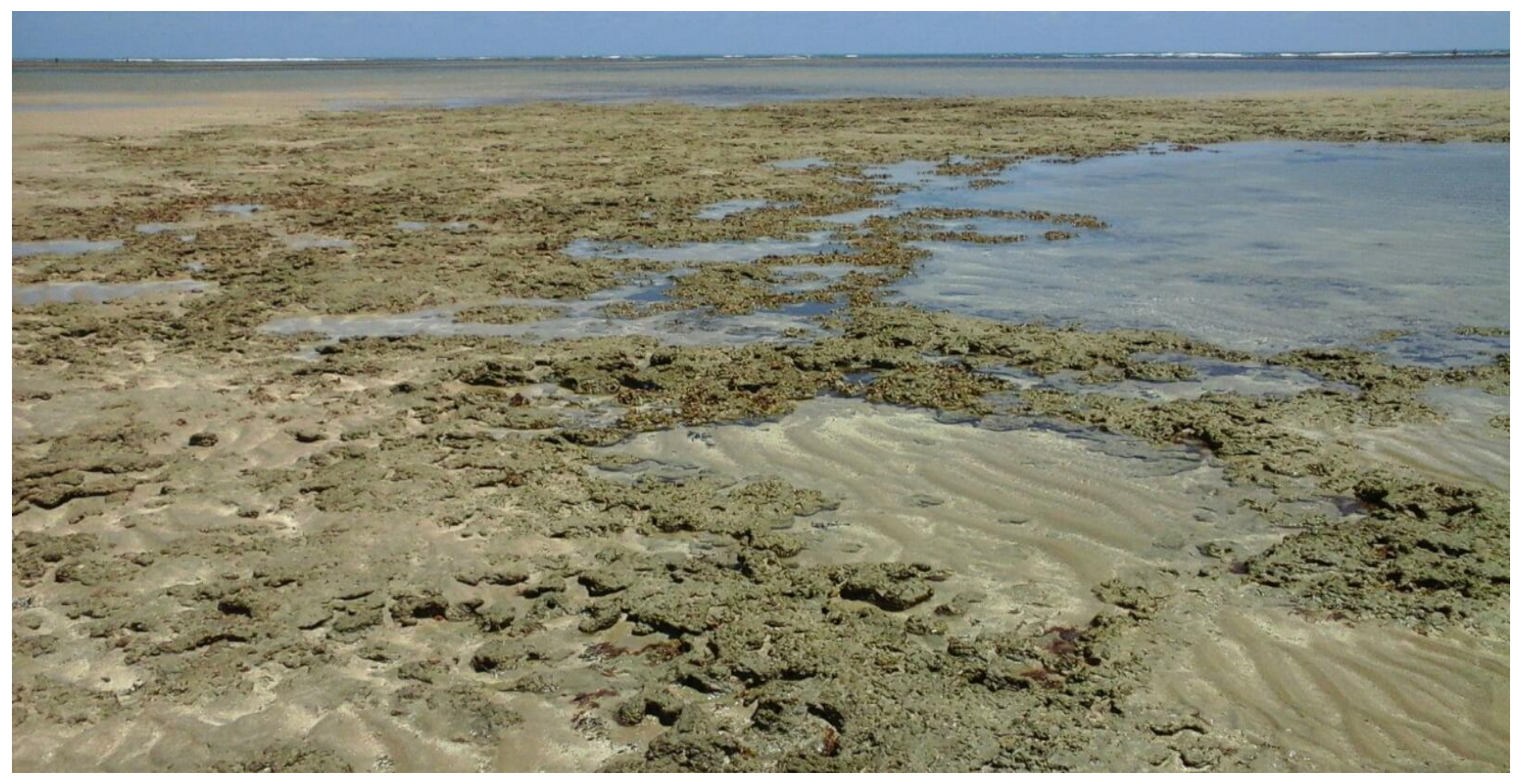

Figura 5: Piscinas naturais formadas por arenitos de praia (beachrocks). Fonte: autores, 2017.

\subsubsection{Clima}

Segundo a classificação de Köppen (1948), o clima da região é do tipo As'- tropical chuvoso, com verão seco - menos de $60 \mathrm{~mm}$ de chuva no mês mais seco - com precipitação pluviométrica anual aproximada de $2.000 \mathrm{~mm}$. A estação chuvosa ocorre de abril a setembro, sendo os meses de maio, junho e julho os mais chuvosos. A estação seca vai de outubro a março, sendo os meses de outubro, novembro e dezembro os mais secos, (INMET, 2005, apud ALMEIDA Jr. et al. 2009). 
XVII Simpósio Brasileiro de Geografia Física Aplicada

I Congresso Nacional de Geografia Física
OS DESAFIOS DA GEOGRAFIA FÍSICA NA FRONTEIRA DO CONHECIMENTO

Instituto de Geociências - Unicamp

Campinas - SP

28 de Junho à 02 de Julho de 2017

\subsubsection{Geomorfologia}

De acordo com Macêdo (2011), os depósitos de praia são sedimentos modernos inconsolidados constituídos por areias quartzosas de granulação que podem variar de areia muito fina a cascalhos (Figura 6). Resultando nos depósitos que se limitam uma faixa de areia que varia em largura em diferentes partes da baía de Maracaípe.

A região é um ambiente altamente dinâmico, que apresenta variações morfológicas constantes, apresentando gradientes de declividades que mudam em função do tamanho do grão e ação do espraiamento das ondas. Nesta matriz arenosa é observável fragmentos de conchas provenientes da plataforma interna adjacente bem como restos vegetais oriundos do estuário (MACÊDO, 2011). Sua faixa de praia apresenta largura variada nem sempre refletindo o estado natural, já que em alguns trechos a póspraia foi aterrada e ocupada.

Por conta das praias visitadas por turistas de todas as partes do mundo, Ipojuca tem, como um dos principais fatores econômicos, o turismo. A rede hoteleira é bastante diversificada, assim como a gastronômica. No primeiro ponto de observação, é possível identificar a presença antrópica na pós-praia, conforme visto na Figura 3. Dentre as causas citadas que contribuem para o processo erosivo, a interferência antrópica é uma das principais, não dando chance para que as variáveis naturais encontrem o seu equilíbrio, porém, não é a única (Figura 7).

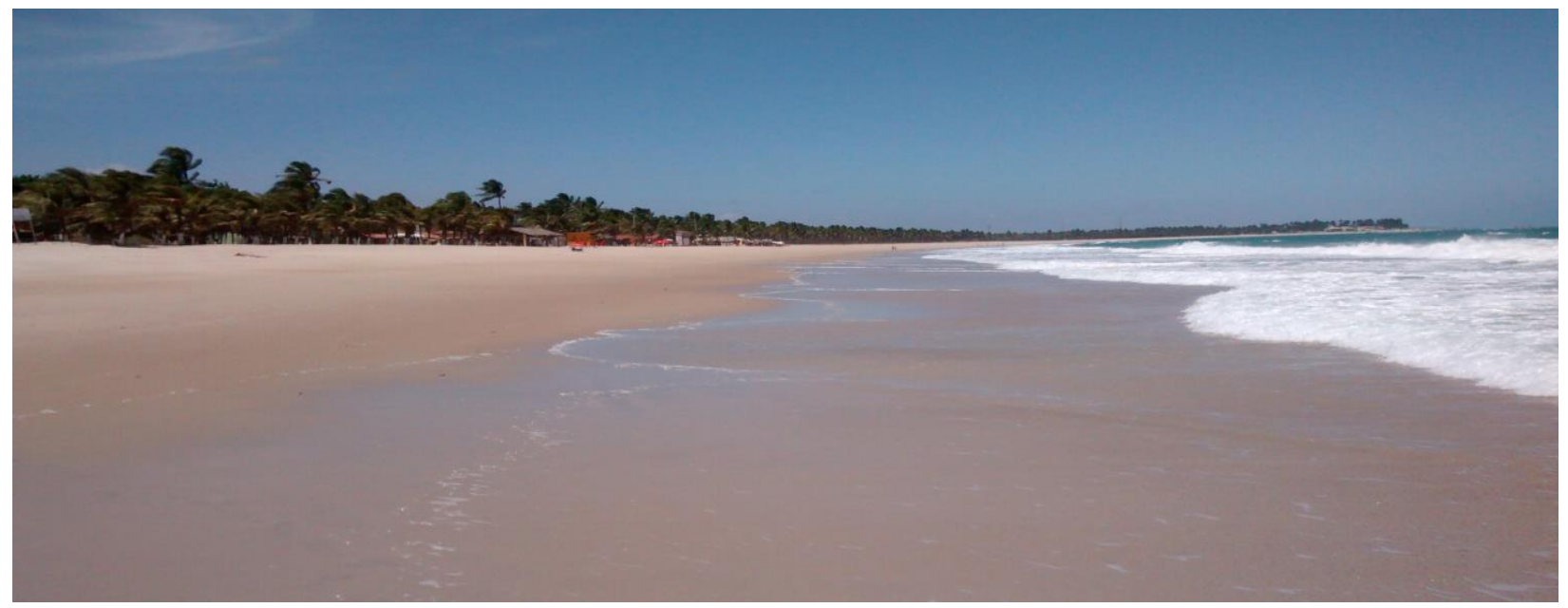




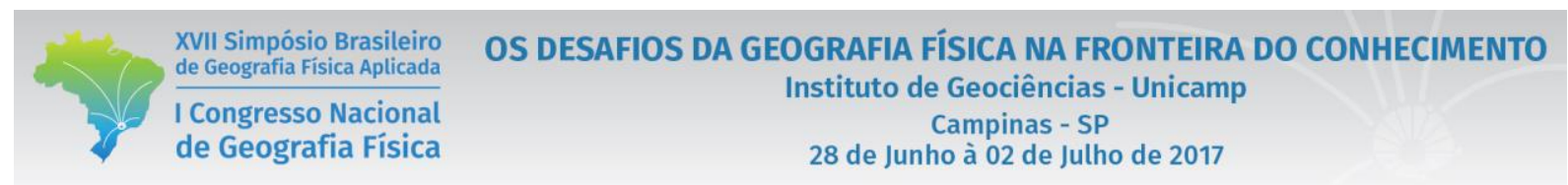

Figura 6. Depósitos de praia na região de Maracaípe. Fonte: autores, 2017.

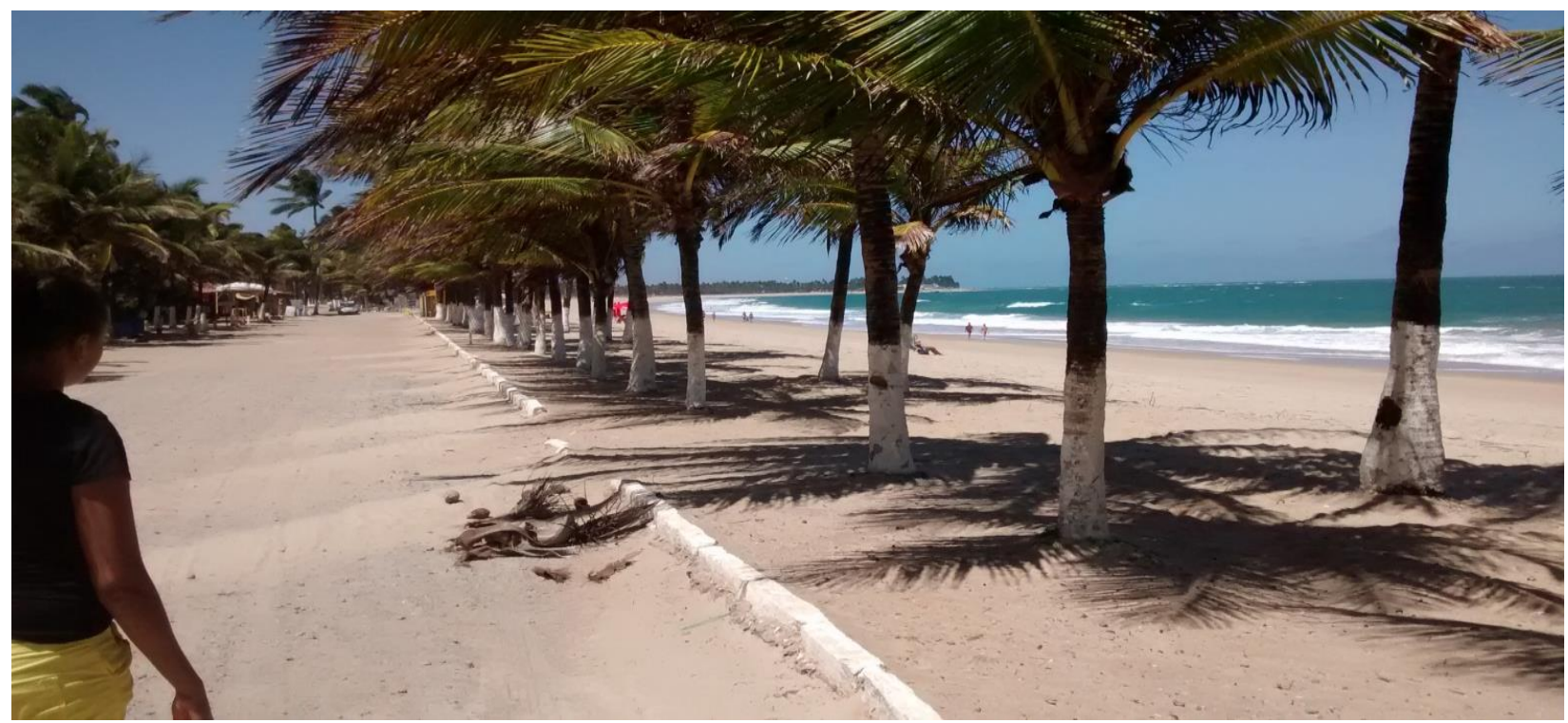

Figura 7: Ocupação urbana na pós-praia, próxima a linha de preamar máxima. Fonte: autores, 2017.

É muito difícil qualificar e quantificar cada um dos fatores que interagem no balanço sedimentar de uma praia e, portanto, é indispensável um trabalho de monitoramento que contemple: perfis de praia com a determinação dos parâmetros da onda (altura, período e ângulo de incidência), tanto na zona de arrebentação como offshore, das correntes e da granulometria dos sedimentos que a formam.

\section{Conclusão}

Tratando-se de uma praia que possui um grande conjunto de ecossistemas naturais a que se tem conhecimento em mangues. Emerge a necessidade de sua Geoconservação e a prática do geoturismo norteada pelos princípios de interdisciplinaridade e sustentabilidade.

É muito importante nesse momento o olhar da esfera pública e privada para esta região. Para que medidas de conservação e organização se voltem para o ambiente. Apoio e medidas podem ser inspiradas a partir da Praia de Porto de galinhas, que devido a forte pressão turística tiveram de se tomar medidas mais efetivas a cerca da conservação dos arenitos, buscando assegurar a integridade dos corais e das demais espécies vivas que dependem desse ecossistema. 
As medidas de conservação devem se estender até Maracaípe, antes que a demanda turística migre com a mesma intensidade que o fez nas piscinas naturais de Porto de Galinhas. Dessa forma, ter-se-ia um forte trabalho de remediação e consequente manutenção desses elementos naturais.

Em Porto de Galinhas foram colocadas barreiras, feitas por cordas para assegurar que banhistas não chegassem ate os pontos mais vulneráveis, o que é uma ação válida. Contudo, sabe-se que se faz necessária toda uma campanha educativa e constante trabalho de monitoramento.

O estudo da orla de Maracaípe apresentou-se bastante eficaz ao detalhar os vários aspectos naturais e antrópicos da área por setores, sendo uma metodologia bastante adequada como via de gestão costeira provendo subsídios para diversos estudos ambientais temáticos como a construção de mapas de vulnerabilidade da costa, mapeamento de zonas para uso e ocupação da orla de forma sustentável, bem como o uso das informações para utilidade pública pela caracterização das áreas de risco para banhistas.

Para isso, sugere-se o desenvolvimento de ações educativas em escolas da comunidade em projetos que possam ser desenvolvidos a distribuição de folders e cartilhas educativas para a conservação da zona costeira, além da participação do poder público, privado e comunidade, sempre pensando no desenvolvimento sustentável, objetivando a garantia da preservação da Geodiversidade e da biodiversidade às gerações futuras.

\section{Bibliografia}

ALMEIDA Jr. et al. Caracterização da vegetação de restinga da RPPN de Maracaípe, PE, Brasil, com base na fisionomia, flora, nutrientes do solo e lençol freático. Acta Botanica Brasilica, 23(1): 36-48, 2009.

BITTENCOURT, A. C. S. P. et al. Evolução paleogeográfica quaternária da costa do estado de Sergipe e da costa sul do estado de alagoas. Revista Brasileira de Geociências. 13(2): 93-97, Junho - São Paulo, 1993.

DOMINGUEZ, J. M. L. et al. Geologia do Quaternário costeiro do estado de Pernambuco. Revista Brasileira de Geociências 20(1-4): 208-215, 1990.

GUERRA, N. C.; KIANG, C. H. \& SIAL, A. N. 2005. Carbonate cements in contemporaneous beachrocks, Jaguaribe beach, Itamaracá island, northeastern Brazil: petrographic, geochemical and isotopic aspects. An. Acad. Bras. Ciênc. 77(2): 343-352.

GUIMARÃES, T. O. Patrimônio geológico e estratégias de geoconservação: Popularização das geociências e desenvolvimento territorial sustentável para o Litoral Sul de Pernambuco (Brasil). Tese de Doutorado apresentada à Pós-Graduação em Geociências do Centro de Tecnologia e Geociências da Universidade Federal de Pernambuco, 359p, 2016.

LIMA FILHO, M. Análise estratigráfica e estrutural da bacia Pernambuco. Instituto de Geociências - USP, São Paulo. Tese de Doutorado, f. 180, 1998. 
MANSO, V. A. V. Definição dos pontos de contorno da linha de preamar máxima atual do litoral do município de Ipojuca - PE. Relatório final, MMA/PNMA 11 - SECTMA N² 249, 2003.

MANSO, V. A. V. et al. Erosão e progradação do litoral Brasileiro. Ministério do Meio Ambiente. Volume Único. Estado de Pernambuco. f. 181, 2011.

MACÊDO, R. J. A. Caracterização morfodinâmica e geoambiental da Praia de Maracaípe, Ipojuca - PE. Dissertação de Mestrado ao programa de Pós-Graduação em Geociências do Centro de Tecnologia e Geociências da Universidade Federal de Pernambuco, 155p, 2011.

MACÊDO, R. J. A. BARRETO, E. P. SANTOS, A. C. MANSO, V. A. V. Estudo geoambiental da orla de Maracaípe - Ipojuca (PE), BRASIL. Estudos Geológicos v. 20 (2), 2010.

PIEKARZ, G.; LICCARDO, A. Turismo Geológico na rota dos tropeiros. Global Tourism. Vol. 3, nº 2. Novembro de 2007. ISSN: 1508-558X, 2007.

RUCHKYS, U. A. Patrimônio Geológico e Geoconservação no Quadrilátero Ferrífero, Minas Gerais: potencial para a criação de um geoparque da UNESCO. Instituto de Geociências, Universidade Federal de Minas Gerais. Belo Horizonte. Tese de Doutorado, 211 p, 2007. 